\title{
Leadless Cardiac Pacemaker: Does Anatomical Position at Implant Affect Long-Term Electrical Performance?
}

\author{
John Ip ${ }^{1}$, Abdul R. Safadi' ${ }^{1}$ Randy Ip ${ }^{1}$, Matthew Gaskill ${ }^{1}$, Rajesh Banker ${ }^{2}$, Derek Exner ${ }^{3}$, \\ Srinivas Dukkipati ${ }^{4}$, Mayer Rashtian ${ }^{5}$, Imran Niazi ${ }^{6}$
}

${ }^{1}$ Cardiac Electrophysiology Department, Michigan State University, Lansing, USA; ${ }^{2}$ Cardiac Electrophysiology Department, Premier Cardiology, Inc, Newport Beach, USA; ${ }^{3}$ Cardiac Electrophysiology Department, Foothills Medical Centre, Calgary, Canada; ${ }^{4}$ Cardiac Electrophysiology Department, Mount Sinai Hospital, New York, USA; ${ }^{5}$ Cardiac Electrophysiology Department, Huntington Memorial Hospital, Pasadena, USA; ${ }^{6}$ Cardiac Electrophysiology Department, Aurora Medical Group, Milwaukee, USA

Correspondence to: John Ip, jip@tciheart.com Keywords: Pacing Lead Location, Leadless Pacing, Lead Impedance, Pacing Threshold, R-Wave Amplitude Received: June 9, 2017 Accepted: November 25, $2017 \quad$ Published: November 29, 2017

Copyright $\odot 2017$ by authors and Scientific Research Publishing Inc.

This work is licensed under the Creative Commons Attribution International License (CC BY 4.0).

http://creativecommons.org/licenses/by/4.0/

\section{(c) (i) Open Access}

\section{ABSTRACT}

Background: The Nanostim \{trade mark, serif\} Leadless Cardiac Pacemaker (LCP) has been shown to be safe and effective in human clinical trials. Since there is little information on the effect of implant location on LCP performance, the aim of this study was to determine whether anatomic position affects the long-term pacing performance of the LCP. Methods: Patients who enrolled in the Leadless II IDE Clinical Trial and had finished 6 months follow up ( $n=479$ ) were selected for the study. The implanting investigators determined the LCP final position under fluoroscope, which was categorized into three groups: RV apex (RVA, $n=$ 174), RV apical septum (RVAS, $n=101$ ), and RV septum (RVS, $n=204$ ) (Figure 1). Data on capture threshold (at a $0.4 \mathrm{~ms}$ pulse width), R-wave amplitude and impedance were analyzed at implant, hospital discharge and 2 weeks, 6 weeks, 3 months and 6 months post-implant. Results: At implant, the mean capture thresholds in the RVA, RVAS and RVS were $0.77 \pm 0.45,0.81 \pm 0.61$ and $0.78 \pm 0.59$ volts, respectively. R-wave amplitudes were $8.0 \pm$ $3.0 \mathrm{mV}, 7.7 \pm 2.9 \mathrm{mV}$ and $7.6 \pm 2.9 \mathrm{mV}$, respectively. Impedance values were $727 \pm 311,765 \pm$ 333 , and $677 \pm 227$ respectively. There were no differences among the 3 implant locations in capture threshold or R-wave amplitudes at 6 months $(P>0.06)$; however, all 3 performance parameters significantly improved over time $(P<0.001)$. Conclusions: The LCP implant location does not affect capture thresholds or R-wave amplitudes at 6 months, and there is little effect on impedance. Although implant location does not appear to be a predictor of electrical performance, additional long-term data will help guide optimal implant location. 


\section{INTRODUCTION}

The permanent leadless cardiac pacemaker (LCP) has been shown to be safe and effective in human clinical trials $[1,3,4]$. Although cardiac perforation during implantation remains a factor for morbidity and mortality in patients undergoing implantation of a permanent LCP, the occurrence rate of this complication is quite low $(1 \%-1.5 \%[1,3,4])$ and is comparable to traditional lead-based systems $[2,3]$. Avoiding the RV apex as an implanting location theoretically might decrease the risk of perforation, however implanters may be hesitant to implant the LCP higher on the RV septum due to the fear of increased pacing thresholds or poor sensing amplitudes that may compromise the performance of the device and/or decrease its longevity. The current recommendation by the manufacturer of the Nanostim ${ }^{\mathrm{TM}}$ LCP (St. Jude Medical) is to implant the device in the RV apical septum. Since there is no information as to how implant location affects LCP performance, the purpose of this study was to determine the impact of anatomical position of the LCP on the long-term electrical performance of the LCP. This might allow easier technique in LCP delivery, implantation; and probably decrease the procedure time, complication, and risk of sedation.

\section{METHODS}

Patients who enrolled in the Leadless II IDE study (NCT02030418) - which was approved by the Institutional Review Board of Sparrow Health system-were selected for analysis. The LCP that was implanted (Nanostim ${ }^{\mathrm{TM}}$, St. Jude Medical) is an entirely self-contained, active-fixation, rate-adaptive pacemaker that is $42-\mathrm{mm}$ long with a maximumdiameter of $6.00 \mathrm{~mm}$. The LCP was delivered to the right ventricle through the use of a specially designed delivery system and was anchored in the right ventricle with the use of a helical screw-in fixation electrode at the distal end of the device. Details regarding this pacemaker and the method of implantation have been previously reported $[1,3]$.

Under fluoroscope, the implanting investigators were allowed to implant the LCP in any position. They were instructed to report the final LCP position. The position of the LCP was determined using fluoroscopy views of RAO 30/LAO 30 as in Figure 1. There were 174 LCP's implanted in the RV Apex, 101 devices implanted in the RV Apical Septum and 204 implanted in the RV Septum.

Each pacemaker was interrogated at the time of implant and just before the patient was discharged from the hospital. Subsequent follow-up interrogations were performed at 2 weeks, 6 weeks, 3 months and 6 months post-implant. At each interrogation, data was collected that included the pacing threshold (at a $0.4 \mathrm{~ms}$ pulse width), R-wave sensing amplitude and impedance. After implant, each patient underwent chest radiography and standard 12-lead electrocardiography. The programming of the pacemaker at implant and at each device interrogation was left to the physician's discretion.

The data were collected and organized in an Excel spreadsheet then imported into the IBM/SPSS statistical package software (Version 22) and reformed into a longitudinal format. The differences between the anatomical locations in electrical measurements were analyzed using a repeated measures analysis of variance (ANOVA).

\section{RESULTS}

\section{* Baseline characteristics}

The demographics of the study population are shown in Table 1. At the time of data cutoff, four hundred seventy nine (479) patients completed 6 months follow up were included in this study. Two hundred ninety six $(61.8 \%)$ of the participants were male, and $183(38.2 \%)$ were female. The mean age was $75.7 \pm 11$ years. Three hundred and sixty three (75.8\%) participants had a history of supraventricular arrhythmia, 183 (38.2\%) with coronary artery disease, and 75 (15.6\%) had congestive heart failure. The mean left ventricular ejection fraction (LVEF) before LCP implantation was 57.6\% $\pm 8.1 \%$.

\section{* Device position}

All LCPs were implanted under fluoroscope. The implanting physician decided the device position after being assessed in two different views LAO 30/RAO 30 (Figure 1).

\section{* Adherence data}




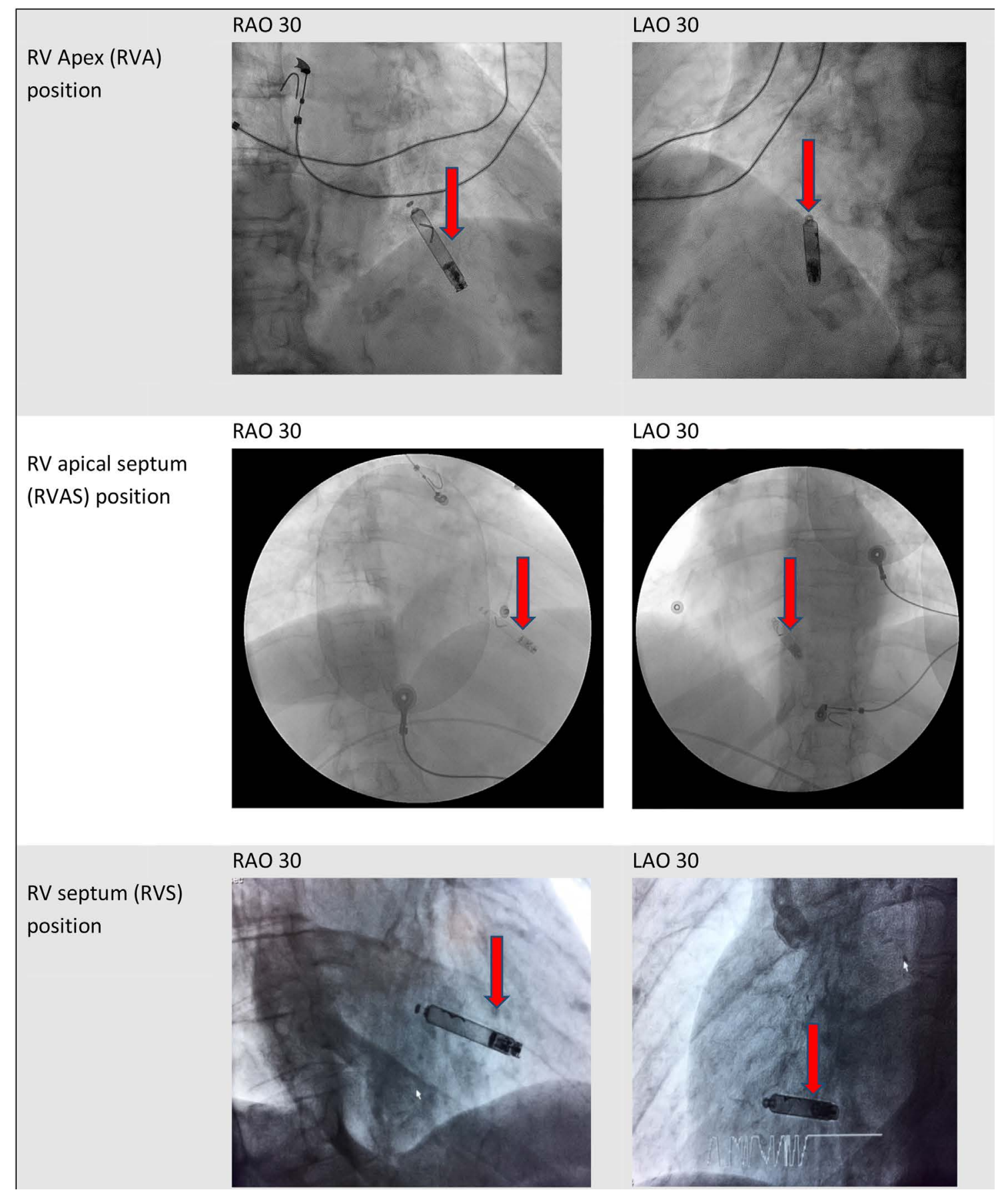

\section{Figure 1. Device position determined under fluoroscope.}

Four hundred seventy nine patients with the LCP implanted who had complete 6-month follow data on the 3 performance parameters were included in the final analysis. The number of patients that were used in the final analysis for each of the 3 performance parameters is shown in Table 1. At implant, the mean pacing capture thresholds in the RVA, RVAS and RVS were $0.77 \pm 0.45,0.81 \pm 0.61$ and $0.78 \pm 0.59$, respectively (Table 2). R-wave sensing amplitudes were $8.0 \pm 3.0 \mathrm{mV} 7.7 \pm 2.9 \mathrm{mV}$ and $7.6 \pm 2.9 \mathrm{mV}$, respectively. The average capture thresholds, R-waving sensing amplitudes and impedances at each device interrogation for each implant location are shown in Table 2, and are plotted against time in Figures 2-4.

Table 3 displays the results of the repeated measures ANOVA, showing that there were significant 
Table 1. LCP final position and Patient characteristics at baseline for subjects included in analysis.

\begin{tabular}{|c|c|}
\hline LCP final position & Cohort $N=479$ \\
\hline - RVA - no. (\%) & $174(36.3)$ \\
\hline - RVAS - no. (\%) & $101(21.1)$ \\
\hline - RVS - no. (\%) & $204(42.6)$ \\
\hline Patient characteristics & Cohort $N=479$ \\
\hline \multicolumn{2}{|l|}{ Age-yr } \\
\hline - Mean & $75.7 \pm 11$ \\
\hline - Range & $30-96$ \\
\hline \multicolumn{2}{|l|}{ Body-mass index } \\
\hline - Mean & $29.2 \pm 7.3$ \\
\hline - Range & $15.8-60.3$ \\
\hline \multicolumn{2}{|l|}{ Sex-no (\%) } \\
\hline - Male & $296(61.7)$ \\
\hline - Female & $183(38.2)$ \\
\hline Coronary artery disease - no. (\%) & $183(38.2)$ \\
\hline History of coronary-artery bypass grafting - no. (\%) & $77(16.0)$ \\
\hline Hypertension - no. (\%) & $382(79.7)$ \\
\hline Diabetes mellitus - no. (\%) & $130(27.2)$ \\
\hline Peripheral vascular disease - no. (\%) & $63(13.1)$ \\
\hline Congestive heart failure - no. (\%) & $75(15.6)$ \\
\hline \multicolumn{2}{|l|}{ History of arrhythmia - no. (\%) } \\
\hline - Supraventricular & $363(75.9)$ \\
\hline - Ventricular & $25(5.2)$ \\
\hline \multicolumn{2}{|l|}{ Tricuspid-valve disease - no. (\%) } \\
\hline Regurgitation or prolapse & $97(20.2)$ \\
\hline Left ventricular ejection fraction - \% & $57.6 \pm 8.1$ \\
\hline
\end{tabular}

variations over time in the capture threshold, R-wave sensing amplitude and impedance; however, there was no evidence of an interaction between time and the device location (group) indicating that locations had similar time-dependent changes in values. The capture threshold decreased after implant in all 3 groups, with the majority of the reduction occurring between implant and hospital discharge (Table 2, Figure 2). At all 3 implant locations, the R-wave sensing amplitude showed an early increase and then tended to plateau between the 3-month and 6-month interrogation (Table 2, Figure 3). There was a decrease in pacing impedance over time in all 3 groups, with the largest change occurring in the first 3 months after implant (Table 2, Figure 4).

A pairwise analysis was performed to compare the pacing performance parameters among the $3 \mathrm{im}$ plant locations (Table 4). This analysis was done using the mean values obtained by averaging the 6 interrogations in each patient. The pairwise analysis showed that there were no significant differences observed in the capture thresholds or R-wave sensing amplitudes among the 3 groups $(\mathrm{P}>0.06)$. There were statistically significant differences in impedance between the RV Apex and RV Septum groups $(P=0.018)$ and 
Table 2. Mean values (capture thresholds, R-wave amplitudes, impedances) at each implant location.

\section{Capture Threshold (average values (SD), in Volts)}

\begin{tabular}{|c|c|c|c|c|c|c|c|c|}
\hline & Location & Implant & Pre-Discharge & 2 Week & 6 Week & 3 Month & 6 Month & Average* \\
\hline \multirow{5}{*}{$\begin{array}{c}\text { Capture } \\
\text { threshold } \\
(\mathrm{N}=479)\end{array}$} & $\begin{array}{c}\text { RVA } \\
(\mathrm{N}=174)\end{array}$ & $\begin{array}{c}0.773 \\
(0.446)\end{array}$ & $\begin{array}{c}0.507 \\
(0.292)\end{array}$ & $\begin{array}{c}0.610 \\
(0.469)\end{array}$ & $\begin{array}{c}0.637 \\
(0.578)\end{array}$ & $\begin{array}{c}0.608 \\
(0.569)\end{array}$ & $\begin{array}{c}0.581 \\
(0.461)\end{array}$ & $\begin{array}{c}0.619 \\
(0.484)\end{array}$ \\
\hline & $\begin{array}{c}\text { RVAS } \\
(\mathrm{N}=101)\end{array}$ & $\begin{array}{c}0.809 \\
(0.609)\end{array}$ & $\begin{array}{c}0.555 \\
(0.583)\end{array}$ & $\begin{array}{c}0.686 \\
(0.735)\end{array}$ & $\begin{array}{c}0.693 \\
(0.758)\end{array}$ & $\begin{array}{c}0.624 \\
(0.480)\end{array}$ & $\begin{array}{c}0.619 \\
(0.526)\end{array}$ & $\begin{array}{c}0.664 \\
(0.626)\end{array}$ \\
\hline & $\begin{array}{c}\text { RVS } \\
(\mathrm{N}=204)\end{array}$ & $\begin{array}{c}0.779 \\
(0.591)\end{array}$ & $\begin{array}{c}0.526 \\
(0.400)\end{array}$ & $\begin{array}{c}0.604 \\
(0.585)\end{array}$ & $\begin{array}{c}0.595 \\
(0.589)\end{array}$ & $\begin{array}{c}0.576 \\
(0.493)\end{array}$ & $\begin{array}{c}0.571 \\
(0.475)\end{array}$ & $\begin{array}{c}0.608 \\
(0.532)\end{array}$ \\
\hline & \multicolumn{8}{|c|}{ R-Wave Amplitude (average values (SD), in milli Volts) } \\
\hline & Location & Implant & Pre-Discharge & 2 Week & 6 Week & 3 Month & 6 Month & Average* \\
\hline \multirow{3}{*}{$\begin{array}{l}\text { R-Wave } \\
\text { Amplitude } \\
(\mathrm{N}=479)\end{array}$} & $\begin{array}{c}\text { RVA } \\
(\mathrm{N}=174)\end{array}$ & $\begin{array}{c}8.010 \\
(3.042)\end{array}$ & $\begin{array}{c}8.814 \\
(2.959)\end{array}$ & $\begin{array}{c}9.486 \\
(2.801)\end{array}$ & $\begin{array}{c}9.721 \\
(2.686)\end{array}$ & $\begin{array}{c}9.883 \\
(2.695)\end{array}$ & $\begin{array}{c}9.769 \\
(2.687)\end{array}$ & $\begin{array}{c}9.280 \\
(2.885)\end{array}$ \\
\hline & $\begin{array}{c}\text { RVAS } \\
(\mathrm{N}=101)\end{array}$ & $\begin{array}{c}7.669 \\
(2.862)\end{array}$ & $\begin{array}{c}8.404 \\
(2.789)\end{array}$ & $\begin{array}{c}9.427 \\
(2.802)\end{array}$ & $\begin{array}{c}9.258 \\
(2.833)\end{array}$ & $\begin{array}{c}9.348 \\
(2.853)\end{array}$ & $\begin{array}{c}9.399 \\
(2.835)\end{array}$ & $\begin{array}{c}8.918 \\
(2.892)\end{array}$ \\
\hline & $\begin{array}{c}\text { RVS } \\
(\mathrm{N}=204)\end{array}$ & $\begin{array}{c}7.597 \\
(2.854)\end{array}$ & $\begin{array}{c}8.284 \\
(3.007)\end{array}$ & $\begin{array}{c}9.037 \\
(3.032)\end{array}$ & $\begin{array}{c}9.207 \\
(2.879)\end{array}$ & $\begin{array}{c}9.270 \\
(2.831)\end{array}$ & $\begin{array}{c}9.139 \\
(2.929)\end{array}$ & $\begin{array}{c}8.756 \\
(2.980)\end{array}$ \\
\hline
\end{tabular}

\begin{tabular}{|c|c|c|c|c|c|c|c|c|}
\hline & \multicolumn{8}{|c|}{ Impedance (average values (SD), in Ohms) } \\
\hline & Location & Implant & Pre-Discharge & 2 Week & 6 Week & 3 Month & 6 Month & Average* $^{*}$ \\
\hline & $\begin{array}{c}\text { RVA } \\
(\mathrm{N}=174)\end{array}$ & $\begin{array}{c}727.59 \\
(311.63)\end{array}$ & $\begin{array}{c}685.06 \\
(200.87)\end{array}$ & $\begin{array}{c}563.97 \\
(170.55)\end{array}$ & $\begin{array}{c}536.67 \\
(158.90)\end{array}$ & $\begin{array}{c}521.32 \\
(148.10)\end{array}$ & $\begin{array}{c}499.66 \\
(141.83)\end{array}$ & $\begin{array}{c}589.04 \\
(214.92)\end{array}$ \\
\hline $\begin{array}{c}\text { Impedance } \\
(\mathrm{N}=479)\end{array}$ & $\begin{array}{c}\text { RVAS } \\
(\mathrm{N}=101)\end{array}$ & $\begin{array}{c}765.15 \\
(333.76)\end{array}$ & $\begin{array}{c}666.24 \\
(222.50)\end{array}$ & $\begin{array}{c}570.59 \\
(193.57)\end{array}$ & $\begin{array}{c}545.05 \\
(160.45)\end{array}$ & $\begin{array}{c}521.68 \\
(163.17)\end{array}$ & $\begin{array}{c}510.40 \\
(162.25)\end{array}$ & $\begin{array}{c}596.52 \\
(232.56)\end{array}$ \\
\hline & $\begin{array}{c}\text { RVS } \\
(\mathrm{N}=204)\end{array}$ & $\begin{array}{c}677.75 \\
(227.59)\end{array}$ & $\begin{array}{c}632.16 \\
(186.02)\end{array}$ & $\begin{array}{c}529.90 \\
(148.88)\end{array}$ & $\begin{array}{c}506.03 \\
(132.73)\end{array}$ & $\begin{array}{c}486.72 \\
(130.87)\end{array}$ & $\begin{array}{c}477.89 \\
(132.41)\end{array}$ & $\begin{array}{c}551.74 \\
(191.47)\end{array}$ \\
\hline
\end{tabular}

*Average of all 6 interrogations. (RVA) Right ventricle apex, (RVAS) Right ventricle apical septum, (RVS) Right ventricle septum.

between the RV Apical Septum and RV Septum $(P=0.016)$, although the absolute differences were small in magnitude. 
Table 3. Repeated measures ANOVA of capture thresholds, R-wave amplitudes and impedances (p-values*).

\begin{tabular}{ccc}
\hline \multirow{2}{*}{ Parameter } & \multicolumn{2}{c}{ Factor } \\
\cline { 2 - 3 } & Time & Time x Location Interaction \\
\hline Capture Threshold & $<0.001$ & 0.910 \\
R-Wave Amplitude & $<0.001$ & 0.666 \\
Impedance & $<0.001$ & 0.123 \\
\hline
\end{tabular}

*Wilks' Lambda test.

Table 4. Pairwise comparisons of capture thresholds, R-wave amplitudes and impedances $\left(\mathrm{p}\right.$-values $\left.{ }^{*}\right)$.

\begin{tabular}{cccc}
\hline \multirow{2}{*}{ Parameter } & \multicolumn{3}{c}{ Pairwise Location Comparison } \\
\cline { 2 - 4 } & RVA vs. RVAS & RVA vs. RVS & RVAS vs. RVS \\
\hline Capture Threshold & 0.417 & 0.811 & 0.300 \\
R-Wave Amplitude & 0.283 & 0.063 & 0.620 \\
Impedance & 0.695 & 0.018 & 0.016 \\
\hline
\end{tabular}

*Based on estimated marginal means with adjustment for multiple comparisons based on least significant differences. (RVA) Right ventricle apex, (RVAS) Right ventricle apical septum, (RVS) Right ventricle septum.

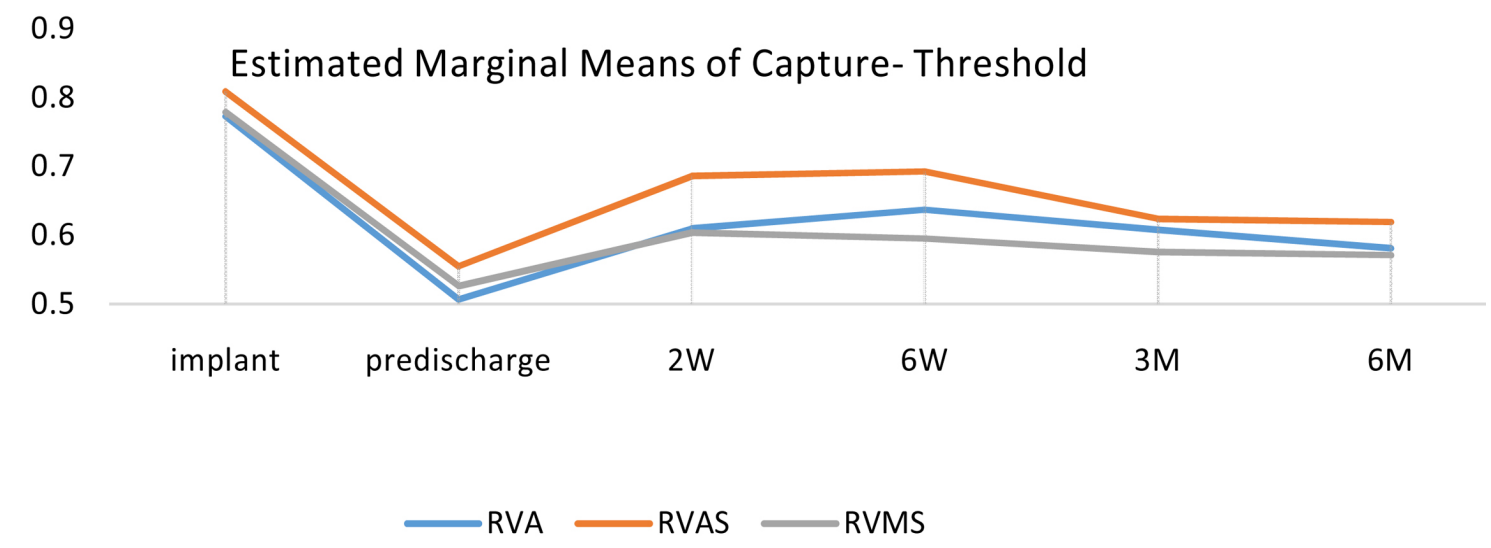

Figure 2. Capture thresholds over time at each final LCP position.

\section{DISCUSSION}

Pacemaker therapy has become the standard of care for the treatment of patients with various bradyarrhythmias. Traditional pacemaker therapy has been shown to enhance quality of life and decrease mortality in high-risk patients [5-7]. Although the effectiveness and safety of transvenous pacemaker therapy have improved over time, this therapy is still associated with procedural- and device-related complications. Approximately $10 \%$ of patients experience a periprocedural complications $[8,9]$, with most 


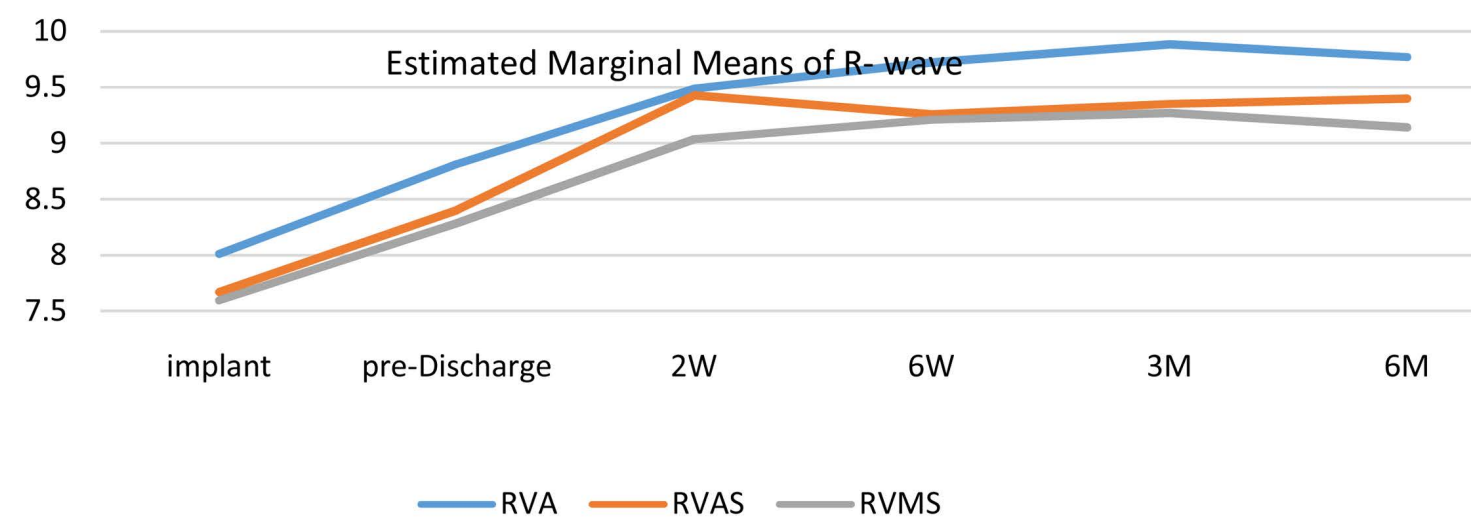

Figure 3. Sensing thresholds over time at each final LCP position.

Estimated Marginal Means of Impedance

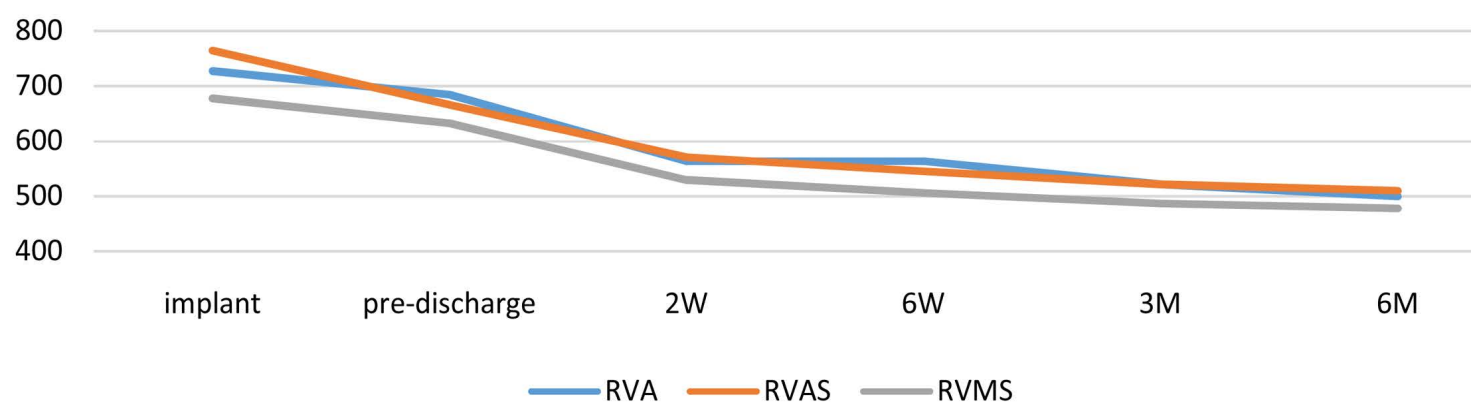

Figure 4. Impedance measurements over time at each final LCP position.

complications related to the subcutaneous pocket of the pulse generator (e.g., hematoma, skin erosion, pocket infection) or venous access and lead implantation (e.g., pneumothorax, cardiac tamponade, lead dislodgment) [10-12].

The LCP was designed to potentially overcome some of these short- and long-term complications and has been shown to be safe and effective in several clinical trials $[1,3,4]$. The manufacturer of the Nanos$\operatorname{tim}^{\mathrm{TM}}$ device recommends that the LCP be implanted in the RV apical septum; however, there is no published information about the performance of the LCP implanted in alternate locations. In addition to reducing the risk of perforation, implantation of the LCP higher on the RV septum might reduce left ventricular dyssynchrony and improve global ventricular performance $[13,14]$.

The present study was performed to evaluate alternative locations for LCP implantation. The most important finding of the present study was that capture thresholds and R-wave sensing amplitudes were not negatively affected by implanting the LCP higher on the ventricular septum. Furthermore, the pacing impedance of the LCP at the two septal locations was similar or lower than the impedance when the LCP was implanted in the RV apex. Thus, our results suggest that the LCP can be placed on the RV septum without compromising pacemaker performance. However, a long term study is needed to compare device longevity. In theory, implantation of the LCP on the RV septum could reduce the ventricular perforation rate and possibly improve ventricular synchrony and performance although this study did not examine this latter effect.

Another finding of the present study was that the 3 pacing performance parameters that were evaluated improved over time, with lowered capture thresholds, improved R-wave sensing amplitudes and decreased impedance values at each location. These findings are similar to those of Knops et al. [15], who evaluated the performance of the Nanostim ${ }^{\mathrm{TM}}$ LCP over a period of 1 year [15]. Although that study did 
not evaluate the effect of LCP location on pacing performance, they reported an early improvement in the capture threshold, R-wave sensing amplitude and impedance. The performance of the LCP became very stable at 3 months, with no further change in the pacing performance at 6 months or 12 months of follow-up [15]. Thus, the improvements in the pacing performance parameters in our study as well as the study by Knops et al. [15] was probably the result of a more stable connection between the device and myocardium as healing and fibrosis occurred.

The results of the present study are encouraging; however, additional studies with a longer duration of follow-up are needed to fully evaluate the pacing performance of the LCP, as these devices last for many years. An important limitation of the present study is that the patients were not randomized to the implant locations since there are no criteria to define those anatomical locations, and thus there could have been selection bias. In addition, future studies should evaluate the impact of long term leadless RV apical pacing versus other location on myocardium function.

\section{CONCLUSIONS}

The LCP implant location does not affect capture thresholds or R-wave amplitudes at 6 months, and there is little effect on impedance. Although implant location does not appear to be a predictor of electrical performance, Optimal LCP implanting location would minimize the risk of perforation or dislodgement, and additional long-term data will help guide implant location. Finally all three performance parameters significantly improved over time.

\section{REFERENCES}

1. Reddy, V.Y., Knops, R.E., Sperzel, J., et al. (2014) Permanent Leadless Cardiac Pacing: Results of the LEADLESS Trial. Circulation, 129, 1466-1471. https://doi.org/10.1161/CIRCULATIONAHA.113.006987

2. Mahapatra, S., Bybee, K.A., Bunch, T.J., Espinosa, R.E., Sinak, L.J., McGoon, M.D. and Hayes, D.L. (2005) Incidence and Predictors of Cardiac Perforation after Permanent Pacemaker Placement. Heart Rhythm, 2, 907-911. https://doi.org/10.1016/j.hrthm.2005.06.011

3. Reddy, V.Y., Exner, D.V., Cantillon, D.J., et al. (2015) Percutaneous Implantation of an Entirely Intracardiac Leadless Pacemaker. The New England Journal of Medicine, 373, 1125-1135. https://doi.org/10.1056/NEJMoa1507192

4. Reynolds, D., Duray, G.Z., Omar, R., et al. (2016) A Leadless Intracardiac Transcatheter Pacing System. The New England Journal of Medicine, 374, 533-541. https://doi.org/10.1056/NEJMoa1511643

5. Epstein, A.E., DiMarco, J.P., Ellenbogen, K.A., et al. (2008) ACC/AHA/HRS 2008 Guidelines for Device-Based Therapy of Cardiac Rhythm Abnormalities: A Report of the American College of Cardiology/American Heart Association Task Force on Practice Guidelines (Writing Committee to Revise the ACC/AHA/NASPE 2002 Guideline Update for Implantation of Cardiac Pacemakers and Antiarrhythmia Devices): Developed in Collaboration with the American Association for Thoracic Surgery and Society of Thoracic Surgeons. Journal of the American College of Cardiology, 51, e1-e62. https://doi.org/10.1016/j.jacc.2008.02.032

6. Andersen, H.R., Nielsen, J.C., Thomsen, P.E., Thuesen, L, Mortensen, P.T., Vesterlund, T. and Pedersen, A.K. (1997) Long-Term Follow-Up of Patients from a Randomised Trial of Atrial Versus Ventricular Pacing for Sick-Sinus Syndrome. Lancet, 350, 1210-1216. https://doi.org/10.1016/S0140-6736(97)03425-9

7. Toff, W.D., Camm, A.J. and Skehan, J.D. (2005) United Kingdom Pacing and Cardiovascular Events Trial Investigators. Single-Chamber versus Dual-Chamber Pacing for High-Grade Atrioventricular Block. The New England Journal of Medicine, 353, 145-155. https://doi.org/10.1056/NEJMoa042283

8. Udo, E.O., Zuithoff, N.P., van Hemel, N.M., de Cock, C.C., Hendriks, T., Doevendans, P.A. and Moons, K.G. (2012) Incidence and Predictors of Short- and Long-Term Complications in Pacemaker Therapy: The 
FOLLOWPACE study. Heart Rhythm, 9, 728-735. https://doi.org/10.1016/j.hrthm.2011.12.014

9. Kirkfeldt, R.E., Johansen, J.B., Nohr, E.A., Jørgensen, O.D. and Nielsen, J.C. (2014) Complications after Cardiac Implantable Electronic Device Implantations: An Analysis of a Complete, Nationwide Cohort in Denmark. European Heart Journal, 35, 1186-1194. https://doi.org/10.1093/eurheartj/eht511

10. Kirkfeldt, R.E., Johansen, J.B., Nohr, E.A., Moller, M., Arnsbo, P. and Nielsen, J.C. (2012) Pneumothorax in Cardiac Pacing: A Population-Based Cohort Study of 28,860 Danish Patients. Europace, 14, 1132-1138. https://doi.org/10.1093/europace/eus054

11. Kiviniemi, M.S., Pirnes, M.A., Eränen, H.J., Kettunen, R.V. and Hartikainen, J.E. (1999) Complications Related to Permanent Pacemaker Therapy. Pacing and Clinical Electrophysiology, 22, 711-720. https://doi.org/10.1111/j.1540-8159.1999.tb00534.x

12. Ellenbogen, K.A., Hellkamp, A.S., Wilkoff, B.L., Camunãs, J.L., Love, J.C., Hadjis, T.A., Lee, K.L. and Lamas, G.A. (2003) Complications Arising after Implantation of DDD Pacemakers: The MOST Experience. American Journal of Cardiology, 92, 740-741. https://doi.org/10.1016/S0002-9149(03)00844-0

13. Saito, M., Kaye, G., Negishi, K., Linker, N., Gammage, M., Kosmala, W. and Marwick, T.H. (2015) Protect-Pace Investigators. Dyssynchrony, Contraction Efficiency and Regional Function with Apical and Non-Apical RV Pacing. Heart,101, 600-608. https://doi.org/10.1136/heartjnl-2014-306990

14. Inoue, K., Okayama, H., Nishimura, K., Saito, M., Yoshii, T., Hiasa, G., Sumimoto, T., Inaba, S., Suzuki, J,. Ogimoto, A., Funada, J. and Higaki, J. (2011) Right Ventricular Septal Pacing Preserves Global Left Ventricular Longitudinal Function in Comparison with Apical Pacing: Analysis of Speckle Tracking Echocardiography. Circulation Journal, 75, 1609-1615. https://doi.org/10.1253/circj.CJ-10-1138

15. Knops, R.E., Tjong, F.V., Neuzil, P., et al. (2015) Chronic Performance of a Leadless Cardiac Pacemaker: 1-Year Follow-Up of the LEADLESS Trial. Journal of the American College of Cardiology, 65, 1497-1504. https://doi.org/10.1016/j.jacc.2015.02.022

\section{ABBREVIATION}

Leadless cardiac pacemaker (LCP), right ventricle apex (RVA), right ventricle apical septum (RVAS), right ventricle septum (RVS). 